\title{
Distribution and Lateral Mobility of GABA/Benzodiazepine Receptors on Nerve Cells
}

\author{
José Luis Velazquez, ${ }^{1}$ Christopher L. Thompson, ${ }^{2}$ Eugene M. Barnes, Jr., ${ }^{2}$ and Kimon J. Angelides' \\ Departments of 'Physiology and Molecular Biophysics and 'Biochemistry, Baylor College of Medicine, Houston, Texas \\ 77030
}

The distribution and mobility of GABA/benzodiazepine receptors has been examined on living nerve cells by fluorescence digital imaging and fluorescence photobleach recovery with 2 novel fluorescent derivatives of the benzodiazepines Ro7-1986 and 1012S. These fluorescent derivatives retain their high affinity for the GABA/benzodiazepine receptor complex with $K_{i} s$ of 79 and $85 \mathrm{nM}$, respectively. Digital fluorescence imaging of GABA/benzodiazepine receptors on rat spinal cord neurons maintained in culture reveal that, even in the absence of observable synaptic contact, GABA/benzodiazepine receptors are localized on the cell body in clusters of very high density. Receptor density on processes is lower than on cell bodies, although occasional areas of intense fluorescence were observed. Fluorescence photobleach recovery measurements show that $70 \%$ of the GABA/benzodiazepine receptors on the cell body and $>85 \%$ on the processes of rat spinal cord neurons are immobile. In comparison, voltage-gated sodium channels are diffusely distributed and very mobile on the cell body $\left(D=10^{-9} \mathrm{~cm}^{2} / \mathrm{sec}\right)$. The results suggest that even in the absence of nerve-nerve cell contact, there are specific mechanisms that segregate GABA/benzodiazepine receptors to the neuronal cell body and control their lateral mobility.

GABA is the most abundant inhibitory neurotransmitter in the CNS and appears to exert its postsynaptic effects via a GABA receptor complex that gates an integral chloride channel. This receptor is modulated by benzodiazepines, which interact with high-affinity binding sites associated with the $\mathrm{GABA}_{\Lambda}$ receptor complex, potentiating GABA-induced conductances (Olsen et al., 1986; Schofield et al., 1987). Knowledge of the distribution of these receptors over the nerve cell surface is scant, yet is clearly important in determining the functional and integrative properties of the neurons that receive these inhibitory inputs. In early studies, photoaffinity labeling with ${ }^{3} \mathrm{H}$-flunitrazepam

\footnotetext{
Received Aug. 15, 1988; revised Oct. 14, 1988; accepted Oct. 21, 1988.

We are grateful to Drs. Simon Gaskell and Peter Haroldsen, Department of Medicine for performing mass spectral analysis, to Dr. Mohammed Tehrani for assistance with the preparation of Figure 3, to Dr. Owen Jones for critical reading of the manuscript, and Wanda Durden for expert help in the preparation of the manuscript. K.J.A. is a recipient of a Research Career Development Award from the National Institutes of Health (K04-NS-01218).

Correspondence should be addressed to Kimon J. Angelides, Department of Physiology and Molecular Biophysics, Baylor College of Medicine, One Baylor Plaza, Houston, TX 77030.
}

Copyright (C) 1989 Society for Neuroscience $0270-6474 / 89 / 062163-07 \$ 02.00 / 0$ and electron microscopic autoradiography was used to define the localization of GABA/benzodiazepine receptors in brain sections (Mohlcr et al., 1980). Such studies, although informative of the location of benzodiazepine receptors at the level of specific central and peripheral nervous system pathways, provide static views of receptor distribution, however.

In order to obtain higher-resolution information concerning the topography and mechanisms governing the distribution of the GABA/benzodiazepine receptor complex on individual nerve cells, we have used fluorescence digital imaging microscopy and photobleach recovery on rat spinal cord neurons stained with 2 novel fluorescent benzodiazepine derivatives. The results suggest that specific mechanisms segregate and immobilize the GABA/benzodiazepine receptor complex to domains on the cell body and that these clements are distinct from those that maintain voltage-gated sodium channels at the axon hillock.

\section{Materials and Methods}

Preparation of fluorescent benzodiazepines. Fluorescent derivatives were prepared by alkylation of the primary amines of $1012 \mathrm{~S}$ and Ro7-1986 by 4-fluoro-7-nitrobenz-2-oxa-1,3-diazole (NBD-F). All reactions were carried out in dim room light and with low actinic glassware. To $20 \mathrm{mg}$ (46 $\mu \mathrm{mol}$ ) of $1012 \mathrm{~S}$ or Ro7-1986 dissolved in $10 \mathrm{ml}$ ethanol with one equivalent of triethylamine added was mixed a 2-fold excess of NBD-F $(18.2 \mathrm{mg}, 90.0 \mu \mathrm{mol})$. The reaction mixture was left at room temperature with constant stirring. The progress of the reaction was monitored by thin-layer chromotography on analytical silica gel $\mathrm{G}$ plates (Analtech). The reaction was complete after $24 \mathrm{hr}$. The solvent was removed in vacuo, the residue was redissolved in chloroform/methanol (1:2), and chromatographed on a $2 \times 40 \mathrm{~cm}$ silica gel $\mathrm{G}$ column eluted with butanol/chloroform (1:2). Relevant fractions were collected and rechromatographed on silica gel $\mathrm{G}$ with chloroform $/$ heptane/methanol (5:5:3) or ethylacetate. In ethylacetate, $R_{f} 1012 \mathrm{~S}, 0.0 ; R_{f}$ NBD-1012S, $0.5 ; R_{t}$ Ro7-1986, 0.72. From $20 \mathrm{mg}$ of starting benzodiazepine we obtained $0.6 \mathrm{mg}$ of purified fluorescent derivative.

The fluorescent derivatives were characterized for their chemical identity by mass spectrometry on a VG Z $\triangle B$ B-SEQ hybrid tandem mass spectrometer operated in the fast bombardment mode. The mass spectra gave molecular ions of 415 and 332 for the benzodiazepines 1012S and Ro-1986, respectively. For NBD-1012S the fragmentation pattern shows the major molecular ion at $597.07\left(\mathrm{MH}^{+}\right)$, corresponding exactly to the predicted molecular mass of NBD-1012S (Fig. 1). The mass spectrometer operated in the tandem mode yielded daughter fragment ions for NBD-1012S $\mathrm{m} / \mathrm{z}$ 448.32, 414 (1012S), 164 (NBD), 138, 87, 166. The fragmentation pattern of NBD-Ro7-1986 gives a major molecular ion at $m / z 495.2\left(\mathrm{MH}^{+}\right)$, corresponding exactly to the calculated mass of NBD-Ro7-1986 (Fig. 1) with daughters at 332.08 (Ro7-1986), 185, 164 (NBD), and 122.

Binding assays. Rat and chicken cortical membranes and membranes from neuronal cultures were prepared and equilibrium hinding assays were performed as described (Tehrani et al., 1985). Membranes prepared from rat brain (100 $\mu \mathrm{g}$ protein) suspended in $20 \mu \mathrm{l}$ of $50 \mathrm{~mm}$ Tris-Cl (pH 7.4) were added to an incubation mixture of ${ }^{3} I$ I-flunitrazepam 
<smiles>O=C(NCCNc1ccc([N+](=O)[O-])c2nonc12)c1nc2c3ccccc3c3c(Cl)cccc3n2n1</smiles>

NBD-1012S<smiles>O=C(CN1C(=O)CN(c2cccc([N+](=O)[O-])c2)c2ccc(Cl)cc21)NCCNc1ccccc1F</smiles>

NBD-Ro1986/001

Figure I. Fluorescent benzodiazepine structures. The fluorescent derivatives were synthesizcd as described in Materials and Methods.

including Ro7-1986 or $1012 \mathrm{~S}$ or fluorescent derivatives in $180 \mu \mathrm{l}$ Tris$\mathrm{Cl}$ (pH 7.4). These samples were mixed and incubated for $30 \mathrm{~min}$ at $4^{\circ} \mathrm{C}$. After this time, two $90 \mu \mathrm{l}$ aliquots were rapidly removed and each added to two $3.0 \mathrm{ml}$ tubes of ice-cold wash medium to stop the binding, filtered on Whatman GF/B filters, and rapidly washed with 3 volumes of ice-cold buffer. Filters were then counted for ${ }^{3} \mathrm{H}$ radioactivity in Scintiverse on a Beckmann LS-1801 Scintillation counter. Nonspecific binding was measured in the presence of a saturating concentration of clonazepam (300 nM) and was subtracted from the total binding. In competition binding studies, increasing concentrations of $1012 \mathrm{~S}$ and Ro7-1986 and their fluorescent analogs were added either to a fixed concentration of ${ }^{3} \mathrm{H}$-flunitrazepam $(8.7 \mathrm{~nm})$ or to test tubes in which the ${ }^{3} \mathrm{H}$-flunitrazepam concentration varied.

Fluorescence microscopy and photobleach recovery. Rat embryonic spinal cord cell cultures were prepared as described (Angelides et al., 1988 ) and plated on 0.11 -mm-thick gridded coverslips coated with collagen or polylysine. Cells were incubated with $50 \mathrm{nM}$ NBD-Ro 7-1986 for $30 \mathrm{~min}$ at $22^{\circ} \mathrm{C}$ in phosphate-buffered saline and rapidly washed 5 times with ice-cold buffer. Fluorescent images of labeled cells were obtained on line with a Hamamatsu VIM photon-counting camera mounted onto a Zeiss Photomicroscope III and through a $63 \times, 1.2$ numerical aperture, water-immersion objective. The attenuated laser beam, using the 457 or $476 \mathrm{~nm}$ lines, served as the illumination source and was dispersed by both a diffusion lens and an opaque rotating disk placed in the exciting light path. The intensifier of the camera was operated in the photon-counting mode. Sets of images were collected in real time, both image and background were acquired sequentially for the total and nonspecific binding. Background-subtracted images were enhanced using a variety of techniques, including histogram stretching, unsharp masking, thresholding, and spatial filtering. Nonspecific binding of the fluorescent benzodiazepine to these cells was measured after addition of $300 \mathrm{~nm}$ clonazepam to the culture dish, incubating for 45 $\min$ at $22^{\circ} \mathrm{C}$, and relocating the same neuron. The fluorescence image from the same cell was obtained under identical optical conditions.

Lateral diffusion coefficients $\left(D_{L}\right)$ and mobile fractions $(f)$ of fluorescently labeled receptors were measured by the spot photobleaching technique using the apparatus described (Axelrod et al., 1976; Henis and Elson, 1981; Angelides et al., 1988). Neuron-bearing coverslips were prepared as described above. After equilibration of the fluorescently labeled ligands at $37^{\circ} \mathrm{C}$, and subsequent washing, the coverslips were mounted inversely either over a serological plate that contained phosphate-buffered saline, for use with a $100 \times$ oil-immersion objective, or by direct placement of a $63 \times$ water-immersion objective into the cell
Table 1. $K_{i}$ values for fluorescent benzodiazepines on rat cortical membranes

\begin{tabular}{|c|c|}
\hline Benzodiazepine & $\begin{array}{l}K_{i} \\
(\mathrm{nM})\end{array}$ \\
\hline $1012 \mathrm{~S}$ & 0.81 \\
\hline NBD-1012S & 85.0 \\
\hline Ro7-1986 & 12.0 \\
\hline NBD-Ro7-1986/001 & 79.0 \\
\hline$\underset{\text { NBD- }\left(\mathrm{CH}_{2}\right)_{2} \mathrm{C}-\mathrm{Ro} 71986}{ }$ & 132.0 \\
\hline 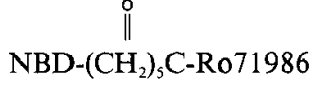 & 163.0 \\
\hline
\end{tabular}

culture dish. The monitoring argon-ion laser $(457,476$, or $488 \mathrm{~nm} ; 5$ $\mu \mathrm{W})$ was focused through the microscope to a Gaussian radius of 0.85 $\mu \mathrm{m}(100 \times$ objective $)$ or $1.2 \mu \mathrm{m}(63 \times$ objective $)$. The illuminated region was bleached by a brief $(10-200 \mathrm{msec})$ laser pulse $(5 \mu \mathrm{W})$. The lateral diffusion cocfficient and the mobile fraction were determined by curvefitting procedures (Angelides et al,, 1988). Incomplete recovery of fluorescence on the time scale of the experiments was interpreted as an immobile fraction of fluorophores $\left(D<1.0 \times 10^{-12} \mathrm{~cm}^{2} / \mathrm{sec}\right)$. Appropriate controls for nonspecific fluorescence were performed by measuring areas devoid of cells or on cells exposed to $300 \mathrm{~nm}$ clonazepam. A sufficiently large number of recordings $(>50)$ was used to statistically analyze and evaluate the differences in measurements between various regions on the neuronal cell surface.

\section{Results}

Fluorescent derivatives of the benzodiazepines, $1012 \mathrm{~S}$ and Ro71986, were prepared by alkylation of the primary amine by 4-fluoro-7-nitrobenz-2-oxa-1,3-diazole (NBD-F). Their structures (Fig. 1) were confirmed by mass spectral analysis.

The derivatives were characterized by competitive displacement of ${ }^{3} \mathrm{H}$-flunitrazepam from rat (Fig. 2) and chicken cortical membranes and membranes prepared from neuronal cultures. The displacement curves indicate that the fluorescent derivatives retain their high affinity for the benzodiazcpinc receptor. The $K_{i}$ values on rat cortical membranes for NBD-1012S and NBD-Ro7-1986 are 85 and $79 \mathrm{nM}$, respectively. Analysis of this data on Hill plots (not shown) gave $n$ values near unity, suggesting a single class of binding site. Nearly identical $K_{i}$ values for the derivatives were obtained on chicken cortical membranes and membranes prepared from cell cultures. Derivatives where the methylene spacer between the parent benzodiazepine and the fluorophore was increased were also active but with generally higher $K_{i}$ values (Table 1). Ro7-1986 and 1012S have been previously employed as ligands for the benzodiazepine receptor (Sigel et al., 1982; Taguchi and Kuriyama, 1984) whose high affinity for displacement of ${ }^{3} \mathrm{H}$-flunitrazepam was also confirmed (Table 1).

The spectral properties of the fluorescent derivatives are also very useful. The excitation maximum is $460 \mathrm{~nm}$, a wavelength that coincides with argon laser lines and with conventional fluorescein filters, while the fluorescence emission maximum is 530 $\mathrm{nm}$. In addition, when the NBD derivatives bind to the receptor, the fluorescence emission maximum is shifted to $515 \mathrm{~nm}$ and is enhanced 35 -fold. Consequently, the contribution of the free ligand to the cell-bound signal is negligible under the conditions employed.

Figure 3 shows the total, nonspecific, and specific staining of a spinal cord neuron labeled with NBD-Ro7-1986. Digital im- 

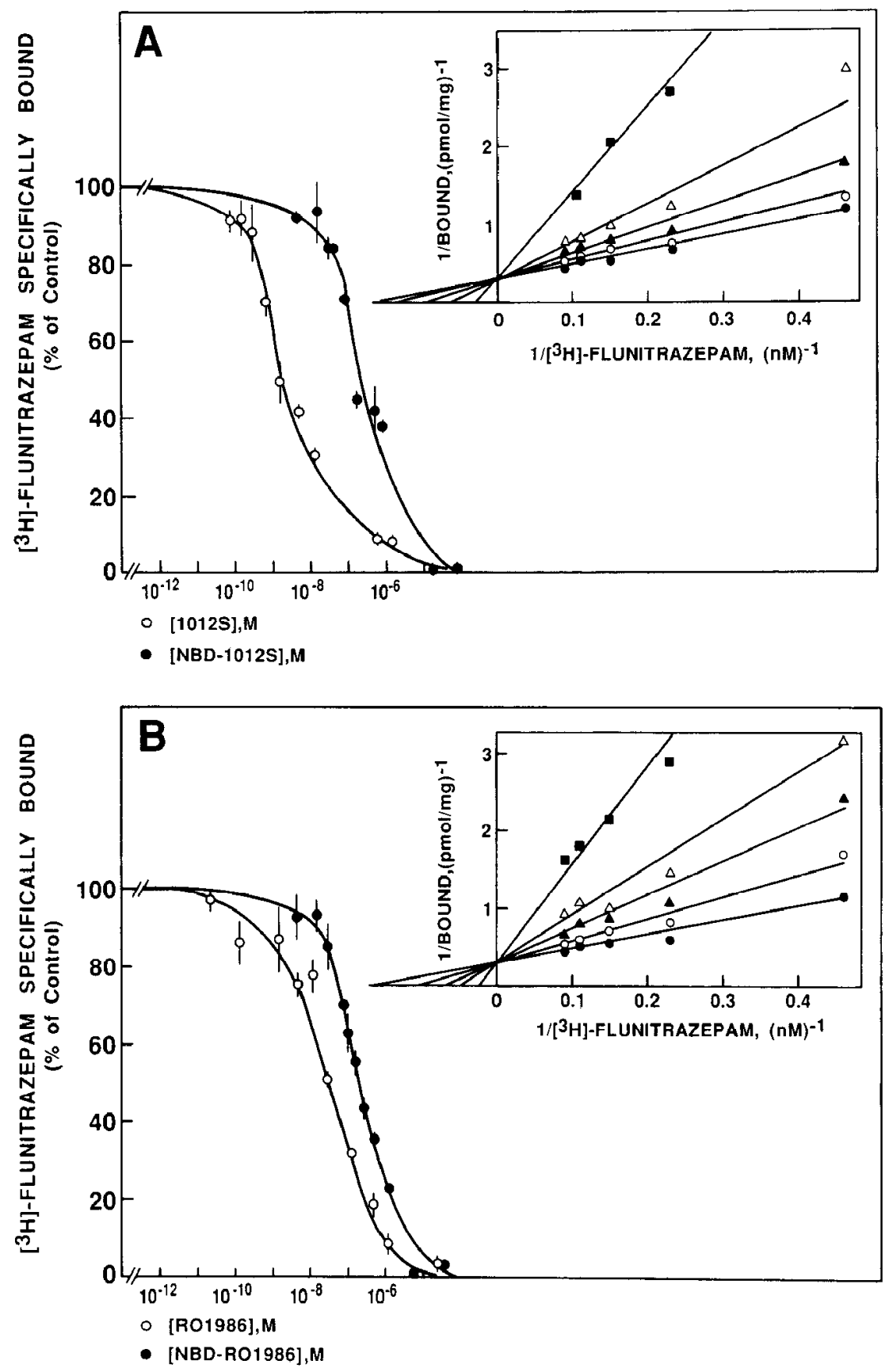

Figure 2. Displacement of ${ }^{3} \mathrm{H}-$ flunitrazepam binding from rat brain membranes by NBD-1012S $(A)$ or NBDRo7-1986 $(B)$. Displacement by the native ligand $(O)$ and by the fluorescent derivative (-). Inset, Double-reciprocal analysis; $\boldsymbol{e}$, denotes absence of NBDderivative; $0,23 \mathrm{~nm} ; \Delta, 67 \mathrm{~nm} ; \Delta, 140$ $\mathrm{nM}$, and $\mathbf{n}, 490 \mathrm{~nm}$ NBD-1012S. 0, 27 $\mathrm{nM} ; \Delta, 81 \mathrm{nM} ; \Delta, 135 \mathrm{nM} ;, 540 \mathrm{nM}$ NBD-Ro7-1986. The inhibition constants for several of the fluorescent derivatives tested are given in Table 1. ages of the fluorescently labeled cells were accumulated to map the distribution of the GABA/benzodiazepine receptor. Evaluation of the digitized and processed images in the absence and presence of $300 \mathrm{nM}$ clonazepam (nonspecific) showed that 300 nM clonazepam, specific for central receptors, reduced the staining greater than $85 \%$ over all parts of the neuron (Fig. $3 C$ ). The image of the specific binding (Fig. $3 D$ ) was obtained by subtracting the digital image of the nonspecific from the total and shows that the highest density of receptors is on the cell body, marked by some clusters of very high receptor density (in violetred). Based upon the fluorescence intensity and series of fluorescent standards, we estimate a receptor density of 800-1000 receptors $/ \mu \mathrm{m}^{2}$ in the densest patches. For most cells, labeling on processes is low to moderate, although occasionally intense labeling is seen on some areas of the processes. The same general staining pattern was observed with NBD-1012S on both spinal cord and cortical neurons. In addition, the specificity of the staining can also be seen by the absence of staining of the underlying non-neuronal cells that form the substratum.

The segregation of GABA/benzodiazepine receptors to the cell body also appears to have some specificity. When tctramethylrhodamine-succinyl-concanavalin A receptors (TmRhds-Con A) or tetramethylrhodamine-phosphatidyl-ethanolamine (TmRhd-PE) were examined, the distribution is homogeneous over all parts of the neuron, indicating that the high GABA/ benzodiazepine receptor density was not due to general glycoprotein aggregation or to local foldings of the membrane that would enhance the fluorescence intensity by increasing the effective surface area. Furthermore, images of doubly labeled neurons show that fluorescently labeled voltage-dependent sodium channels are diffusely distributed on the cell body (not shown).

To gain insight into what mechanisms the neuron may utilize 


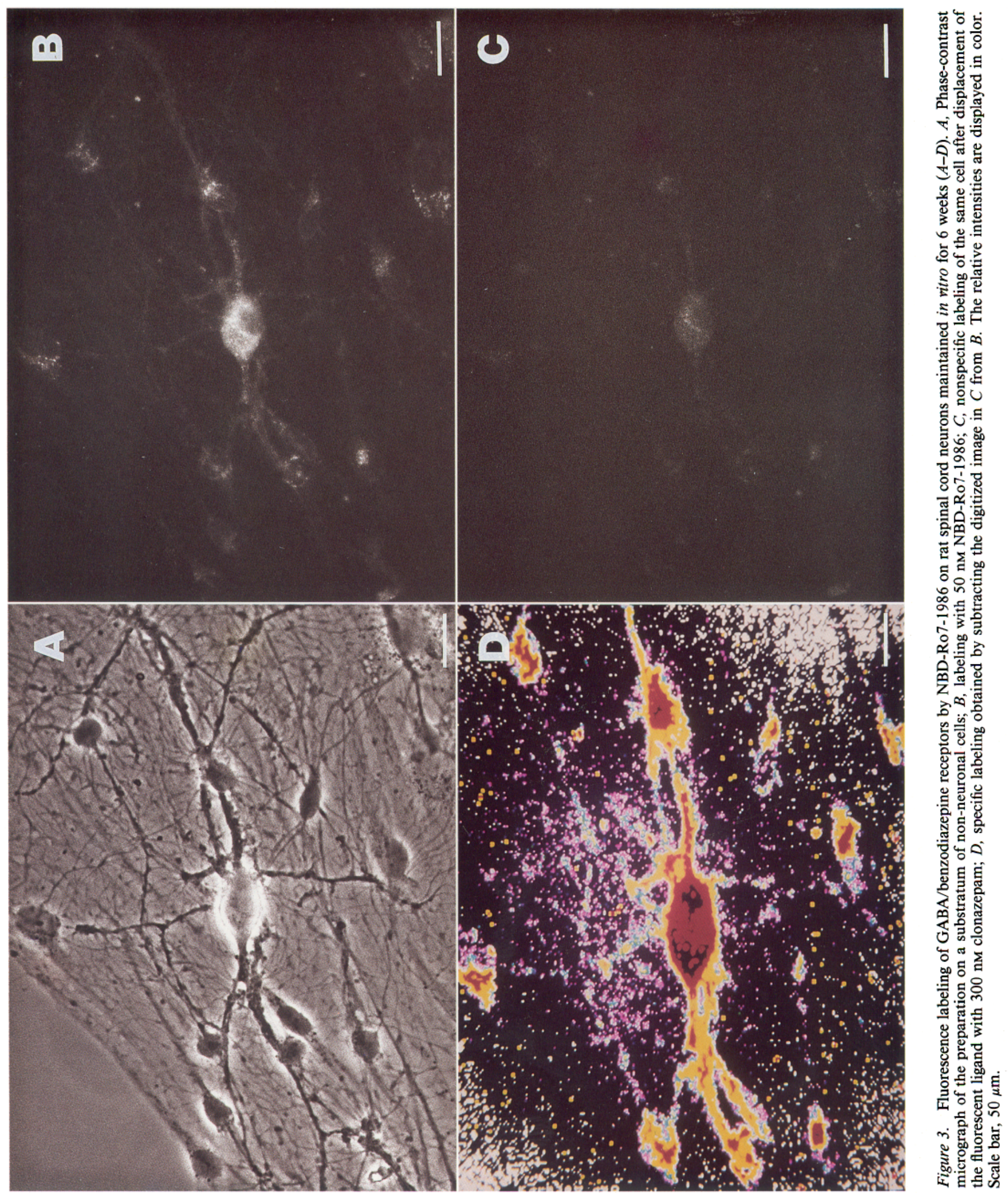



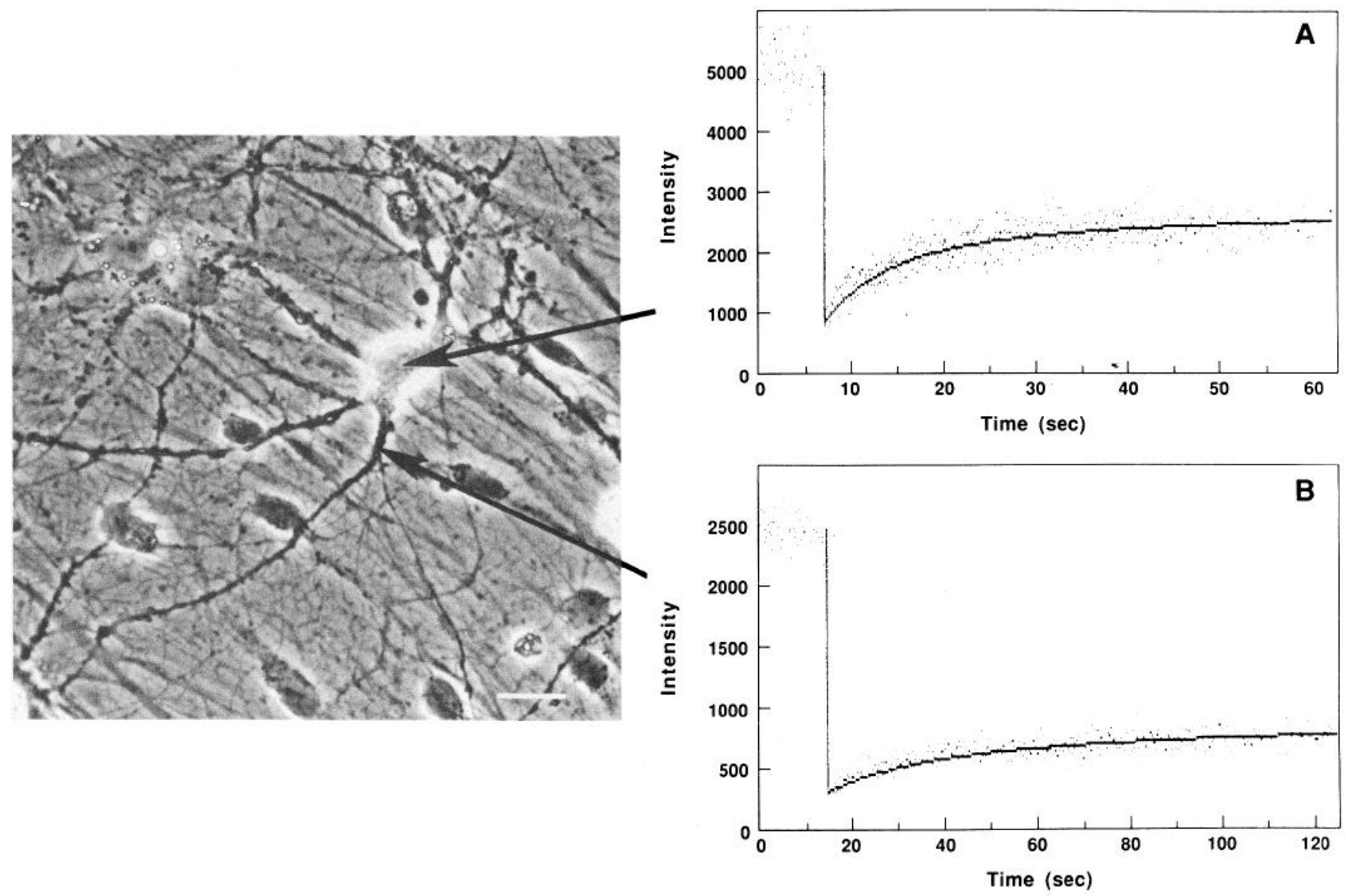

Figure 4. Representative fluorescence photobleach recovery curves on rat spinal cord neurons (6 weeks in vitro) demonstrating slow or partial mobility of GABA/benzodiazepine receptors on the cell body $(A)$ or cell process $(B)$. The curves were obtained using 50 nM NBD-1012S at the locations indicated. Analysis of the curve in $A$ yields a diffusion coefficient of $2.85 \times 10^{-10} \mathrm{~cm}^{2} / \mathrm{sec}$ and a recoverable fraction of $36 \%$ for the GABA/benzodiazepine receptor. In $B$, the diffusion coefficient was $0.38 \times 10^{-10} \mathrm{~cm}^{2} / \mathrm{sec}$ and a recoverable fraction of $18 \%$. Competition by 300 nM clonazepam reduced the fluorescence signal by $80-90 \%$. The fluorescence remaining after displacement appeared more homogenously distributed and diffuse on the cell surface and represents nonspecifically bound ligand. Photobleaching of the nonspecific component shows complete $(f=1.0)$ and rapid recovery $\left(D=10^{-8} \mathrm{~cm}^{2} / \mathrm{sec}\right)$. Thus, the nonspecific component does not contribute to the recovery measured.

to organize and maintain GABA/benzodiazepine receptor distribution on the cell body, we measured the lateral mobility of fluorescently labeled GABA/benzodiazepine receptors by FPR (Fig. 4). FPR shows that most of the GABA/benzodiazepine receptors on the cell body of rat spinal cord neurons are immobile, with $30 \pm 9 \%$ of the receptors able to move at ates of $2.0 \times 10^{-10} \mathrm{~cm}^{2} / \mathrm{sec}$ (Table 2). On processes, fewer than $20 \%$ of the receptors are mobile and the rate of lateral motion of these receptors was at least 5 -fold slower than the mobile class on the cell body. Photobleaching in regions of either high or low receptor density in the cell body showed no differences in the immobile fraction or recovery rates; mobility/immobility appears to be independent of the local receptor density. The low fractional mobility on processes is also not due to diffusion into a limited membrane area (Angelides et al., 1988) because the membrane area of the processes is 2-3 times larger than the diameter of the spot photobleached. The mobilities of succinylCon A receptors and phospholipids, on the other hand, were essentially the same in all regions of the neuron (Table 2). The results demonstrate that the distribution and the mobility of the GABA/benzodiazepine receptor complex is not a general characteristic of neuronal cell proteins, nor are the mobility prop- erties a result of differences in membrane fluidity in the cell body created by partitioning of particular phospholipids, or regional domains created by aggregation of glycoproteins.

In comparison, all of the diffusely distributed voltage-dependent sodium channels labeled with tetramethylrhodamine-Lqq V (TmRhd-Lqq) (Angelides et al., 1988) on the cell body are rapidly mobile with diffusion coefficients of $10^{-9} \mathrm{~cm}^{2} / \mathrm{sec}$ (Table 2).

Immobilization of the GABA/benzodiazepine receptor complex is also found on cultured chick cortical neurons. However, some differences were found (Table 2). Compared with rat spinal cord neurons, these differences consisted mostly of a larger fraction of labeled receptors that were mobile. Among other factors, this could reflect differences in development between these neurons. Indeed, in preliminary studies we have found that as maturation proceeds, even in the absence of any observable nervenerve cell contacts, a greater fraction of GABA/benzodiazepine receptors become immobilized to the cell body.

\section{Discussion}

In this study we have employed novel fluorescent derivatives of 2 high-affinity benzodiazepines to map the distribution and 


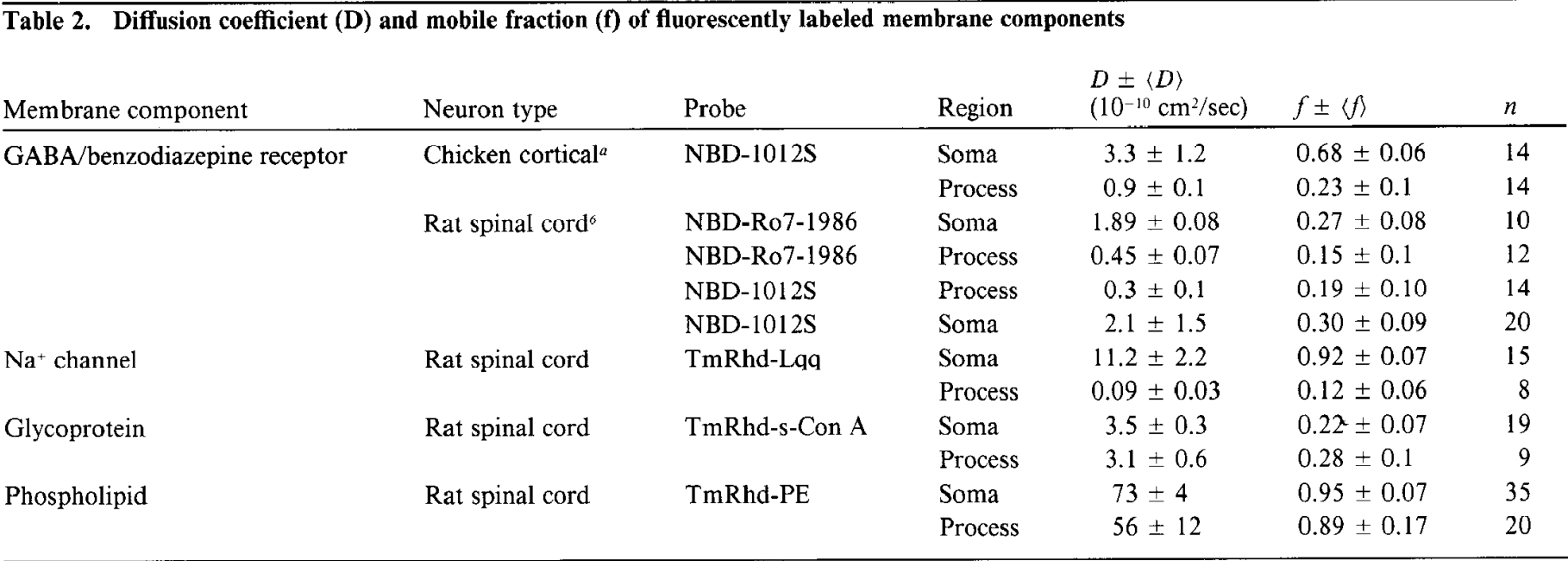

\footnotetext{
a $\mathrm{d}$ in culture.

b. 4-6 weeks in culture.
}

mobility of the GABA/benzodiazepine protein complex on individual neurons. The highest density of receptors is on the cell body, where the fluorescence is distinctly punctuate. Some processes were also seen to have dense receptor clusters. The segregation of GABA/benzodiazepine receptors into hot-spots confirms and extends earlier electrophysiological studies of spinal cord neurons that showed that GABA-mediated conductances were concentrated at foci of high sensitivity on cell bodies and proximal dendrites (Choi and Fischbach, 1981). Comparison of the distribution of voltage-dependent sodium channels by double-labeling experiments shows that on the same neuron sodium channels are sparse and diffusely distributed on the cell body but concentrated at the initial segment and at foci along the axon (Angelides et al., 1988), regions where GABA/benzodiazepine receptors seem to be excluded. The absence of patches of succinyl-Con A receptors, phospholipids, or voltage-dependent sodium channels colocalizing with GABA/benzodiazepine receptor complexes on the cell body shows that the neuron forms and maintains a distinct distribution of different mcmbranc proteins. This segregation also appears to occur in the absence of any observable nerve-nerve cell contact. Thus, these dense regions of GABA/benzodiazepine receptor clusters appear to develop independent of innervation and may precede synapse formation. More experiments are needed to investigate this point.

It seems likely that the forces and factors that limit the mobility also contribute to the regional localization of the receptors. The forces that retard GABA/benzodiazepine receptor mobility and distribution could arise from several kinds of interactions: (1) It is possible that an impermeable barrier, like a corral that defines domains within the cell body, or between the cell body and the processes prevents movement of the receptors between rcgions. Such a barrier would have to be highly selective since it would block diffusion of GABA/benzodiazepine receptors but allow other proteins and lipids to diffuse freely between these regions; or (2) the receptor may interact directly with the specialized cytoskeleton established in the cell body.

There is biochemical evidence from the differential solubilities of the receptor to support the idea that GABA/benzodiazepine receptors are associated with cytoskeleton. These studies have suggested that type II receptors are Triton-soluble and are not attached to the cytoskeleton, while type I receptors found in Triton-insoluble fractions may be associated with the cytoskeleton (Gee and Yamamura, 1983; Lo et al., 1983). While isoforms of brain spectrin and ankyrin have been shown to bind to voltage-dependent sodium channels and control their lateral mobility, these same proteins do not appear to be associated with the ${ }^{3} \mathrm{H}$-flunitrazepam/benzodiazepine receptor (Srinivasan et al., 1988). These results suggest several possibilities, including differences in the sequence of the GABA/benzodiazepine receptor cytoskeletal binding domain, ankyrin isoforms that specifically associate with the GABA/benzodiazepine receptor complex, or cytoskeletal elements other than ankyrin and spectrin that control GABA/benzodiazepine receptor complex distribution and mobility. In purified preparations of the glycine receptor, a $93 \mathrm{kDa}$ protein that copurifies with the ligand binding site is thought to be a cytoskeletal protein (Schmitt et al., 1987). In light of the extensive homologies between the GABA and glycine receptor, such a cytoskeletal protein may also associate and immobilize GABA receptors. In addition, recent cDNA studics suggest multiple forms of the GABA/benzodiazepine receptor complex are present in brain (Levitan et al., 1988). It is possible that these subtypes are region/domain specific and form associations with as yet undiscovered GABA-specific cytoskeletal proteins or subtypes of brain ankyrin. Further experiments will be required to address these points.

In conclusion, the GABA/benzodiazepine receptor complex is localized and immobilized on the cell body. It is important now to reveal those elements that maintain this organization and the mechanisms that the neuron uses to segregate the GABA benzodiazepine receptor complex selectively during neuronal development.

\section{References}

Angelides, K. J., L. W. Elmer, D. A. Loftus, and E. L. Elson (1988) Distribution and lateral mobility of voltage-dependent sodium channels in neurons. J. Cell Biol, 106: 1911-1925.

Axelrod, D., D. E. Koppel, J. Schlessinger, and E. L. Elson (1976) Mobility measurements and analysis of fluorescence photobleaching recovery kinetics. Biophys. J. 16: 1055-1069.

Choi, D. W., and G. D. Fischbach (1981) GABA conductance of chick spinal cord and dorsal root ganglion neurons in cell culture. J. Neurophysiol. 45: 605-620.

Gee, K. W., and H. I. Yamamura (1983) Benzodiazepine receptor 
hetcrogeneity: A consequence of multiple conformational states of a single receptor or multiple populations of structurally distinct macromolecules? In Pharmacology of Benzodiazepines, E. Usdin, P. Skolnick, J. F. Tallman, D. Greenblatt, and S. M. Paul, eds., pp. 93-108, Verlag Chemie, Basel.

Henis, Y., and E. L. Elson (1981) Inhibition of the mobility of mouse lymphocyte surface immunoglobulins by locally bound concanavalin A. Proc. Natl. Acad. Sci. USA 78: 1072-1076.

Levitan, E. S., P. R. Schofield, D. R. Burt, L. M. Rhee, W. Wisden, M. Köhler, N. Fujita, H. F. Rodriguez, A. Stephenson, M. G. Darlison, E. A. Barnard, and P. H. Seeburg (1988) Structural and functional basis for $\mathrm{GABA}_{\mathrm{A}}$ receptor heterogeneity. Nature 335: 76-79.

I o, M. M. S., S. M. Strittmatter, and S. H. Snyder (1983) Physical separation and characterization of two types of benzodiazepine receptors. Proc. Natl. Acad. Sci. USA 79: 680-694.

Mohler, H., M. K., Battersby, and J. G. Richards (1980) Benzodiazepine receptor protein identified and visualized in brain tissue by photoaffinity label. Proc. Natl. Acad. Sci. USA 77: 1666-1670.

Olsen, R. W., J. K. Wamsley, R. J. Lee, and P. Lomax (1986) Benzodiazepine/barbiturate/GABA receptor chloride ionophore complex in a genetic model for generalized epilepsy. Adv. Neurol. 44: 365 375 .

Schmitt, B., P. Knaus, C. M. Becker, and H. Betz (1987) The $M_{r} 93000$ polypeptide of the postsynaptic glycine receptor complex is a peripheral membrane protein. Biochemistry 26: 805-811.
Schoch, P., J. G. Richards, P. Haring, B. Takacs, C. Stahli, T. Staehelin, W. Haefely, and H. Mohler (1985) Co-localization of GABA $A_{A}$ receptors and benzodiazepine receptors in the brain shown by monoclonal antibodies. Nature 314: 168-171.

Schofield, P. R., M. G. Darlison, N. Fujita, D. R. Burt, F. A. Stephenson, H. Rodriguez, L. M. Rhee, J. Ramachandran, V. Reale, T. A. Glencorse, P. H. Seeburg, and E. A. Barnard (1987) Sequence and functional expression of the $\mathrm{GABA}_{\mathrm{A}}$ receptor shows a ligand-gated receptor superfamily. Nature $320: 221-227$.

Sigel, E., C. Mamalaki, and E. A. Barnard (1982) Isolation of a GABA receptor from bovine brain using a benzodiazepine affinity column. FEBS Lett. 147: 45-48.

Srinivasan, Y., L. W. Elmer, J. Q. Davis, V. Bennett, and K. J. Angelides (1988) Ankyrin and spectrin associate with voltage-dependent sodium channels in brain. Nature 333: 177-180.

Taguchi, J., and K. Kuriyama (1984) Purffication of GABA receptor from rat brain by affinity column chromotography using a new benzodiazepine, 1012S, as an immobilized ligand. Brain Res. 323: 219 226.

Tehrani, M. H., C. J. Clancey, and E. M. Barnes, Jr. (1985) Multiple $\left[{ }^{35} \mathrm{~S}\right] \mathrm{t}$-butylbicyclophosphorothionate binding sites in rat and chicken cerebral hemispheres. J. Neurochem. 45: 1311-1314. 